\title{
Erratum to: Special Issue of Spotted Wing Drosophila
}

Published online: 10 June 2016

(C) Springer-Verlag Berlin Heidelberg 2016

\section{Erratum to: J Pest Sci}

DOI 10.1007/s10340-015-0692-9

DOI 10.1007/s10340-016-0730-2

DOI 10.1007/s10340-016-0737-8

DOI 10.1007/s10340-016-0733-z

DOI 10.1007/s10340-016-0731-1

Unfortunately, the special issue note has been missed in the original publication for 4 articles and has been incorrectly published in article DOI 10.1007/s10340-016-0731-1. The correct special issue note is provided in this erratum.

"Special Issue: Spotted Wing Drosophila". 